\title{
The Research of Vacant Housing in China Based on the "Smart Growth" Theory
}

\author{
Li Huang \\ College of Economics \& Management, University of Sichuan Agriculture \\ 46 Xin Kang Road, Ya'an 625014, China \\ Tel: +86-131-5854-3513Ｅ-mail:huangli198611@sina.com.cn \\ Wenkuan Chen (Corresponding author) \\ College of Economics \& Management, University of Sichuan Agriculture \\ 46 Xin Kang Road, Ya'an 625014, China \\ Tel: +86-139-8017-9889 E-mail: cwk9889@yahoo.com.cn
}

Xuanzi Wei

College of Economics \& Management, University of Sichuan Agriculture

46 Xin Kang Road, Ya'an 625014, China

Tel: +86-152-8351-2862 E-mail: weixzdq@yahoo.com.cn

Ping Huang

School of Economics \& Management, University of Sichuan Agriculture

46 Xin Kang Road, Ya'an 625014, China

Tel: +86-132-8169-0612Ｅ-mail: jiang6714@163.com

Received: November 1, $2010 \quad$ Accepted: November 16, $2010 \quad$ doi:10.5430/jms.v1n1p63

\begin{abstract}
Aiming at the outstanding housing problems of the high vacancy rate in our country, on the basis of analyzing the reasons for existing vacant housing, we used the smart growth theory as a guide to solve the problem of vacant housing, and to reduce resource waste caused by vacant housing from three aspects, namely setting the boundary of urban development, using compact planning model of "TOD” (Transit-Oriented Development) and revitalizing existing vacant housing.
\end{abstract}

Keywords: Smart growth, Housing vacancy, City development boundary, "TOD”

At present, the problem of vacant housing has been concerned by more widespread community in China, the phenomenon of vacant housing that talked by people is used to referring to the completed real estate that have not yet been saled. However, we cannot ignore another vacant phenomenon: the houses have been sold but have not been occupied. Recently, the notes of an article entitled to "China's vacant residential is the milk of capitalists" caused by a number of media attention: "there are 6540 million vacant housing units in the 660 cities nationwide, and they enable 2 million people to live in". The local group of economic half-hour CCTV for the problem of vacant housing conducted an in-depth investigation in the satellite towns of the capital, the results are not optimistic: the occupancy rate of the vast majority of newly developed real estate are less than 1/3, when night fell, the high buildings became black light district. While the rumor that there are 6540 million vacant housing units in China is implausible, but in addition to the basic living function, housing also have investment function and the potential performance capabilities, making the speculative demanding occupy prodigious proportion and the vacant housing stocked in the amount of housing is much higher than the number of housing for sale; the local governments in order to pursuit the political achievements, making the residential building projects as the Image Projects, and they supply the land unlimitedly, making theconstruction of 
urban residential housing emerged unlimited low-density development trends, resulting in a large number of idle housing and the land are used inefficiently. Therefore, at the premise of urban sustainable development, how to solve the problem of vacant housing effectively, making the vacant houses used rationally, become the current problems to be solved. So the "Smart Growth" is becoming an effective theory to solve the problem that the big city expands unlimitedly, which advocates saving and intensive use of land, limiting urban sprawl, protecting the city and the surrounding ecological environment, contributing to the idea of sustainable urban development. The "TOD" theory, the urban growth boundary and the urban waste land reused could provide some inspiration for solving the problem of vacant housing.

\section{The "Smart Growth" theory}

The Smart Growth theory was formed in the 1990s, and it is available in Europe on the basis of Mill theory, it's also the deepening concept of sustainable oriented view for urban development. The "Smart Growth" theory and the "compact city" theory has a close relationship, to a big degree it uses the "compact city" theory as references. And it is also the exploration and practice of the "compact city" theory in the United States (Yi, H., and Zhu, D., 2006, pp.66-67).

"Smart growth" is a comprehensive strategy covered various aspects of urban development, it make the urban development blend in the regional ecosystem and the goal of the harmonious development between human and society. It presents the "TOD" that the public transport-led of development unit, "urban growth boundaries", and the Reuse of urban wasteland, etc. (Zhang, J., and Li, J., 2006, pp.45-48). This theory received broad public support in the United States, while also received the official's response, most states have promulgated the relevant planning regulations. Smart Growth also identified 10 principles: mixed land use; walkable communities; compact building design; offers a variety of transportation choices; protection of open space, farmland, natural landscape and the important area of the environment; attractive communities; To build houses that could meet the needs of people who have various income levels; strengthening the existing community development; to make development decisions predictable, fair and cost-effectiveness; and the public participation(Li, D., and Chen, L., 2008, pp.26-27). The core of its principles is make full use of the urban space, reducing the blind expansion of city; strengthen the reconstruction of existing community, To redevelop the abandoned land and the land polluted by the industrial in order to save the cost of infrastructure and public services; the relative concentration of urban construction, the use of intensive group, life and employment units as far as possible draw closer, reducing infrastructure, housing construction and use costs. Among them, the staggered layout of residential area, office space and commercial space, which concentrated in the centers of the city, they are the content that the advocates of "smart growth" mostly concerned about.

\section{Analysis of the situation and the reason of vacant housing}

In order to statistic the vacancy rate of housing, there are a wide variety of private statistical methods such as drying meter method, drying water method, tanning lamp method, check property method. In short, the statistical methods of vacant housing in China are further discussion. In addition, how many vacant houses are there in China? Authorities still did not make the authoritative statistics, and there are many difficulties in the statistic. For example, if you want to calculate the vacancy rate, the vacancy rate's numerator and denominator must to be determined, if the two fundamental problems are not uniform, or no basic consensus, then discussing the problem of the vacancy rate make no sense. However, it is certain that, the vacant estate are mainly the following four categories: First, the suburban residential areas and some high-grade residential villas; Second, the investment houses, the Owners of the house constantly changing, making it uninhabited; Third, amphibious building dish for both dwelling and commerce, the owners can afford to buy it, but cannot afford the property management fees, mostly for investment; Fourth, the owners do not have real estate license, the house cannot be traded. Just as these four types of real estate make the vacancy rate has been high. So, from the current situation, the reasons to leading the vacant housing existed are:

(1) The high demands of investment and speculation lead to the vacant housing. In recent years, with the rapidly increase in housing prices, investing the real estate has become the object that most people concerned. Particularly the investment ratio of the real estate in the good location is higher. Take Hainan Province for example, the first half of this year, the real estate investment completed 20.533 billion Yuan, up (over the previous year) increased by $78.9 \%$, and the investment of commercial housing accounts for $90 \%$ in the total investment. Statistics showed that more than $70 \%$ of real estate in Hannan are exported off the island in recent years, some residential areas up to $90 \%$ vacancy rate, the waste of resources is every serious.

(2) Facilities uncompleted cause the housing vacancy. Currently, a planning concept is popularized by government: Government take the money from saling the land to build facilities. first of all, selecting a block of gross area, and speculating the block, and then sell it at high prices, after the property the developers developed have been put into use, the hardware facilities has not keep up with it, so the regional facilities are not matured. For example, some local 
governments plan a large number of development zones and University City in urban suburban or urban-rural, So that many developers come to invest in housing, people know that the facilities in the short term cannot keep up with it, but there are great opportunities for long-term development, so they buy them at reduced prices and holding for a long period, put the houses into a real investment house.

(3) The absence of special plans boosts the housing vacant. In recent years, with the elevation of urbanization level, the phenomenon of suburbanization in China is increasingly spreads to the suburbs. Thanks for the lack of special programs such as the overall urban planning and detailed planning, plus the fact of local governments in pursuit of performance, making the residential building projects into the image, and the GDP index promote the project of making the empty town to develop. Taking Beijing as an example, the number of population, announced by the official, have breakthrough twenty million, growing at an annual increase in the number of hundreds of thousands. Expansion of cities is inevitable; Beijing-Hebei-Tianjin integration is the trend. But the plans far from to keep up with the city development, local governments do things on their own way, this will inevitably lead to the phenomenon as the "sleep city" Yanjiao.

\section{The Inspiration of the Smart Growth Theory to the problem of vacant housing}

\subsection{The Inspiration of urban growth boundary theory to the problem of vacant housing}

A huge issue that brought about by urban sprawl is making urban-rural boundary become blurred. Therefore, how to distinct boundaries between the urban and rural clearly, protect the natural landscape and agricultural areas are the core content in controlling the spread of the city. To set the "urban growth boundary" is an increasingly popular and effective way to control the development area into a specified area. Draw a line that the scope of urban develop allowed, set aside a number of "the proposed development area" for the development of corporate to develop, each new zone is isolated by the permanent green belt and connected by the public transport, and then choosing the different development densities according to the needed, and giving the border a certain flexibility so that it can be adjusted when necessary (Zhang, T., 2005, pp.44-48). Practice has been proved that the role of urban growth boundaries not only to set a barrier to prevent the spread of urban disorderly, but also to set important Nature Conservation and the recreation of the public, more importantly, to provide reasonable grooming for the future urban development(Tang, X., 2008, pp.87-90).

Therefore, in the face of the trend of the urbanization and suburbanization at the same time in china, when we want to solve the problem of vacant housing, in order to further prevent the waste of resources caused by the development of construction of urban housing, the Government should set the urban development boundary or urban service boundaries, and manage the location and the process of the development, To limit the urban development in a well-defined and geographic area connected geographic area To stop urban sprawl, and also help for restricting the extensive expansion of the city land used by housing construction. the setting of the Urban development boundary or urban service boundaries is conductive to limit local government provide for the land blindly, thus contributing to limit the geographical scope of housing construction, and can effectively control the incremental area of vacant housing, to achieve the development of compact urban housing. In fact, to control the incremental area of vacant housing is the fundamental method to solve the problem that the vacant housing rate grows excessively. However, to control the incremental area, in addition to the precision marketing strategies the real estate developers rely on, more important is the government's control and mastery of the approval system of land. The Government should conduct a reasonable and effective housing construction plan, to avoid a significant increase of the housing supply in a short time and the oversupply would be the future's vacant room.

\subsection{The Inspiration of "TOD” Theory to the problem of vacant housing}

The "TOD" theory emphasizes that using the land mixedly, connecting the residential, commercial, office and other functional units together by public transport, retaining substantial amounts of green open space between the each unit. It is characterized by emphasis on that the patterns of land use is mixed. The bus site come to be the regional transport hub, helping improve the utilization rate of public transport, encourage walking, etc (Li, T., and Chen, T., 2005, pp.251-253). The needs of urban housing leads to the needs of the urban transport, public transport are convenient or not, impacts on people's production and life directly. At present, most of the vacant houses belonging to the suburbs so-called New town or satellite town, its facilities are not perfect, and there is no industry support. When the Government increases area of housing construction, they also should be increase the area of public facilities construction like the transportation. However, in the setting of urban development boundary conditions, increasing the area of housing construction, meanwhile, increasing the area of traffic and other public facilities appears to be impossible. But that is not the case, this problem can be resolve by the "TOD" planning model. Through the implementation of "TOD" mode, the first is connecting the public transport and residential, commercial, office and other functional units together, and then to encourage people to walk; Second, designing the public transport sites rationally to make people make full use of public transport to work, while constructing the bicycle lanes and walking trails. Through the "TOD" compact development pattern that will help reducing the housing vacancy caused by incomplete facilities. 


\subsection{The Inspiration of reusing abandoned land within the urban theory on the problem of vacant housing}

The theory of reusing the abandoned land in the Urban, in essence, is the re-development of cities and regions, mainly referring to update the functions of the internal cities, it emphasize the city's wasteland are reused, and try to make the decline industry area glow the energy again. While developing in the existing cities rather than rural areas (Liu, C., and Shen, Q., 2002, pp.55-58).

At present, China showing a conflict situation that housing vacancy and the basic needs exist in the same time: one side is a lot of people cannot afford housing, on the other side many people have the houses but they are not to live, and the proportion of it is not low, which brought a serious waste of social resources. These vacant rooms that no one to live in like as the abandoned land in the inside city. So how to reuse these "waste land" is the issue that the government decision-makers should attach great importance to. Now, in order to solve the housing problems of the people, the Government spends lots of money to build affordable housing, public rent housing and so forth. Rather than doing this, it would be better to use the existing vacant room efficiently or activate the secondary rental market, make these black light district re-lit warm light when night falls. Therefore, the Government may choose a representative area, draft and issue uniformly the special planning of activating the vacant land, come forward to activate the existing vacant housing, and then promote the rental and selling housing market to develop in a healthy and orderly direction. Government can also impose a large number of vacant taxes; forcing people put the vacant room into rental market.

In addition, in order to prevent the government from providing the land blindly caused by pursuit of GDP growth, do the image projects vigorously, so the Government should be re-enact the performance evaluation criteria. For example, whether the Government has developed the other industries, and guided capital to a reasonable investment channel, changed the people's investment manner and reduced the speculation in the real estate industry; Whether declined the housing vacancy rate and revitalized the existing housing stock; Whether activated the housing rental market, or monitored and evaluated the rental market strictly and so on.

\section{The Conclusions and policy recommendations}

With the rapid development of China's urbanization process, the housing construction increased sharply and gradually eroded the farmland of rural areas and the ecological environment of surrounding. The absence of the special planning and public facilities is seriously lagging behind, resulting in a large number of idle urban housing, making the use of urban land resources inefficiently. To avoid this phenomenon sprawl, governments should be based on the principles of sustainable land use, draft the relevant policy measures to reduce housing vacancy rate. From the urban smart growth theory, the method of control the urban vacant housing mainly in the following areas:

(1) Set the urban development boundary. Related departments should do a good job overall urban planning, set the urban development boundaries or urban service boundaries, limit the local governments provide the land blindly, and then control the scope of housing construction in the area, it is very helpful to control the incremental area.

(2) Use the "TOD" planning model. Vacant housing, not just the result of speculation, the other reason is the public facilities incomplete, especially the real estate developed newly in suburban, where the public transport and other facilities cannot meet the needs of people in a short time. Therefore, when the public transport and housing, commercial and office and other functional units together, and design the public transports rationally. The "TOD" theory can curb the urban sprawl effectively and reduce the adverse effects caused by car trips.

(3) Activate the existing vacant room. serious waste of resources caused by large number of vacant housing, while the Government for the purpose of performance, construct large number of economic and suitable houses, public rental houses and other image projects, but it also exacerbate the waste of land resources. Therefore, the Government should make a number of ways to activate the existing stock housing, activate the secondary rental market, to achieve the reuse of vacant rooms.

(4) Change the government's evaluation system of performance. Assessing local government's record in the past simply by the development of GDP, and even formed "only GDP" theory, Local government to make money by selling a large number of land what they collected and take up a lot of farmland. Therefore, changing the current performance appraisal system, encouraging the Government to lead the masses to realize the upgrading of the industrial structure and guide the funds transfer from the real estate into the other reasonable investment fields. Which can effectively reduce their housing investment (speculative) demand; the relative can also reduce the supply of the land. 


\section{References}

Li, D., Chen, L., and Zhao, K. (2008). The enlightenment to Chinese intensive land use based on the Theory of "Smart Growth". Journal of Shanxi Architecture, 34, 26-27

Li, T., and Chen, T. (2005). Coordinated development of Land use and urban transport-a research on Theory and Practice of "TOD” in Modern American. Journal of South Architecture, 5, 251-253

Liu, C., and Shen, Q. (2002). The connotation of "New Urbanism" and its enlightenment. Journal of Modern Urban Research, 1, 55-58

Tang, X. (2008). Interpretation of New Urbanism and smart growth. Journal of Urban Problems, 1, 87-90

Yi, H., Zhu, D., and Liu, D. (2006). Urban transformation: from linear growth to smart growth. Journal of Price Theory and Practice, 7, 66-67

Zhang, J., and Li, J. (2006). The enlightenment to Chinese urban expansion based on American "Smart Growth". Journal of City Management Science \& Technology, 5, 45-48

Zhang, T. (2005). Control the spread of urban land: a global problem. City planning, 1999, 44-48 